\title{
Sobre la expulsión de diputados "tránsfugas" La quiebra del Grupo Parlamentario Adelante Andalucía
}

\author{
Victor 7. Vázquez
}

Son muchas las páginas escritas sobre la naturaleza jurídica del grupo parlamentario y sobre el necesario espacio de autonomía conceptual de esta realidad con respecto a los partidos políticos, no obstante, son recurrentes también los supuestos en que, usando la expresión en su día empleada por Rubio Llorente, los hechos nos obligan a "vernos como somos", es decir, a dar cuenta de las carencias prácticas de tal autonomía teórica. Si los partidos políticos son entes privados de base asociativa, expresión por tanto del artículo 22 de la Constitución española, y regulados a través de las Ley orgánica de Partidos Políticos; los grupos parlamentarios son, por su parte, concreción en el ámbito institucional parlamentario, del derecho de participación política del artículo 23.1, siendo el reglamento parlamentario su marco de regulación jurídica. Partiendo de esta síntesis diferenciadora, se acude comúnmente a la imagen de la "correa de transmisión" para evidenciar el hecho de que los grupos parlamentarios son tributarios, en sede institucional, de la lógica del estado de partidos. Es así, cuando dicha lógica de facción se expresa, el momento en el que se produce la tensión entre la teórica realidad institucional del grupo parlamentario y su naturaleza política. Como es conocido, la jurisprudencia constitucional delimitó en una temprana jurisprudencia los límites de esta discusión, al afirmar, con relación al célebre art.11.7 de la Ley 39/1978, de 17 de julio, sobre Elecciones Locales, que preveía que "si alguno de los candidatos electos dejare de pertenecer al partido que le presentó, cesará en su cargo", que dicha sanción infringía "de manera absolutamente frontal el derecho de los ciudadanos a participar en los asuntos públicos por medio de representantes y también el de los representantes mismos a mantenerse en sus funciones" . En cualquier caso, pese a este asidero conceptual, la incidencia de los partidos políticos, en tanto entes de relevancia constitucional, en la comprensión del mandato representativo, es algo incuestionable, tal y como el propio Tribunal Constitucional ha reconocido en diversas ocasiones². No sé si es posible afirmar que

\footnotetext{
1 SSTC, 20/1983, de 15 de marzo, fundamento jurídico 3 y 5/1983, de 4 de febrero, fundamento jurídico 4 .

2 Véase, por ejemplo, la STC 119/1990: "...quienes han sido elegidos para el desempeño de funciones representativas (...) han solicitado y obtenido el voto de los electores para orientar su actuación pública dentro del marco constitucional en un sentido determinado (...) Los Diputados son representantes
} 
nos encontramos aquí ante una suerte de mutación constitucional en lo referido a la prohibición del mandato imperativo, tal y como en su momento sugiriera Pedro de $\mathrm{Vega}^{3}$, pero sí que un mínimo de realismo en nuestra interpretación de la realidad político constitucional nos obliga a ver la relación entre el representante y el partido como una relación de extrema lealtad, cuya quiebra si bien no conlleva la pérdida del cargo electo, sí puede suponer un límite en determinadas facetas del derecho al ejercicio de dicho cargo ${ }^{4}$.

De los muchos escenarios en los que puede manifestarse esta relación conflictiva entre mandato parlamentario y lealtad a la facción política, uno de ellos es aquel en el que dicha fricción entre el diputado y el partido político en cuyas listas concurrió a las elecciones, da lugar a la ruptura de este con su formación política, ya sea por su propia voluntad o por su expulsión.

Nos movemos aquí, obviamente, en el campo genérico del transfuguismo, un fenómeno que se ha entendido repugna a las exigencias de calidad democrática de las instituciones legislativas. Calidad que entre otras cosas dependería, para no defraudar la opción electoral que toman los ciudadanos sobre la lista de candidatos que el partido ofrece, de la cohesión y unidad política en torno a la formación ideológica de los cargos representativos electos. No es esta mera crónica parlamentaria el lugar para profundizar en la cuestión de qué es el transfuguismo y si podría deslindarse un transfuguismo virtuoso de otro nocivo para la democracia, en cualquier caso, sí cabe subrayar una tendencia que es la de extender el concepto de tránsfuga más allá de la quiebra en la pertenencia al partido, a toda una serie de acciones desleales a la línea política determinada por la asociación.

De entre los distintos instrumentos concretados frente a los efectos nocivos de la conducta tránsfuga, destaca sobre todos el "Acuerdo sobre un código de conducta política en relación con el transfuguismo en las corporaciones locales", que suscribieron el 7 de julio de 1998 la mayoría de las fuerzas políticas que disfrutaban entonces de representación parlamentaria. Un acuerdo cuya última Adenda se ha recién incorporado, con fecha de 11 de noviembre de 2020, con el objeto expreso de ampliar las medidas hasta entonces acordadas a todos los niveles de gobierno, promoviendo modificaciones normativas de urgencia, y, en concreto, de los reglamentos de las Cá-

del pueblo español considerado como unidad, pero el mandato que cada uno de ellos ha obtenido es producto de la voluntad de quienes los eligieron determinada por la exposición de un programa político jurídicamente lícito (...) La fidelidad a este compromiso político, que ninguna relación guarda con la obligación derivada de un supuesto mandato imperativo, ni excluye, obviamente el deber de sujeción a la Constitución que ésta misma impone en su art. 9.1, ni puede ser desconocida ni obstaculizada".

3 PEDRO DE VEGA GARCÍA, "Significado constitucional de la representación política", Revista de estudios políticos, N. ${ }^{\circ} 44$.

4 Sobre el contenido de este derecho es obligada la cita a la STC, 32/1985. 
maras 5 . La mención expresa a los reglamentos de las cámaras no es casual, y es que, de hecho, y más allá de aquellas regulaciones existentes de la figura del diputado no adscrito y su estatus jurídico, las implicaciones parlamentarias del transfuguismo y, en concreto, la eficacia de las medidas de expulsión del grupo, son un ámbito desregulado en la gran mayoría de cámaras autonómicas ${ }^{6}$.

Es en este contexto de desregulación -que es siempre a su vez de incertidumbre, cuando se trata del ejercicio de derechos fundamentales- donde se inscribe una de las polémicas más relevantes, desde la perspectiva del derecho parlamentario, de la presente legislatura. Se trata, como puede intuirse, de la expulsión del grupo parlamentario de Adelante Andalucía, de los diputados, Teresa Rodríguez Ángela Aguilera, José Ignacio García, Luz Marina Dorado, María Vanessa García, María Gracia González, Nacho Molina y Diego Crespo. La imputación de transfuguismo tiene su origen en el abandono por parte de éstos de su militancia en Podemos, formación a través de la cual lograron sus escaños, dentro de la coalición Adelante Andalucía.

Consumado el hecho del abandono de su militancia, en aras de dar forma a una corriente propia anticapitalista, el 28 de octubre de 2021, la portavoz parlamentaria del grupo Adelante Andalucía comunicó a la mesa del parlamento andaluz la baja de dicho grupo parlamentario de los representantes mencionados con anterioridad. La mesa del Parlamento andaluz no sólo admitirá a trámite dicha comunicación, sino que dará a la misma, en un principio, una suerte de efectos constitutivos, resolviendo que desde ese momento dichos parlamentarios quedan fuera del grupo Adelante Andalucía, pasando a ser diputados no adscritos a todos los efectos.

Como más arriba se señalaba, sobre este ámbito del derecho parlamentario pesan importantes lagunas regulatorias, sin que el Reglamento del parlamento andaluz sea aquí la excepción que confirma la regla. A este respecto, la única referencia que encontramos en la norma parlamentaria andaluza es el artículo 24.1 del Reglamento que determina que quien causara baja en el grupo parlamentario adquirirá necesariamente la condición de Diputado o Diputada No Adscrito, sin que exista ninguna otra norma que discipline este procedimiento ni concrete cuál ha de ser el alcance de la supervisión que la Mesa del Parlamento ha de llevar a cabo, en aquellos supuestos en los que se quiere dar eficacia a la baja de determinados diputados en el grupo parlamentario.

A este respecto, lo cierto es que en un primer momento la Mesa del Parlamento andaluz se limitó a admitir a trámite y dar efectos inmediatos a dicha baja, como

\footnotetext{
5 El texto está disponible en: https://www.mptfp.gob.es/dam/es/portal/prensa/notas_de_prensa/notas/2020/11/adendaIII.pdf\#page=1

6 Es de especial interés y utilidad el trabajo de ESTELA GILBAJA CABRERO, "La figura del parlamentario no adscrito", CORTS. Anuario de derecho parlamentario, núm. 28, 2015.
} 
si se tratase de un mero acto de toma de conocimiento de la expulsión del grupo parlamentario de los diputados, es decir, absteniéndose de cualquier tipo de supervisión y con plena deferencia hacia el criterio del grupo expresado por su portavoz. Un automatismo que es sin duda problemático, ya que, como es sabido, el tránsito al estatus de diputado no adscrito implica una disminución sustancial en la capacidad que los parlamentarios van a tener para poder participar activamente en la vida de la cámara, más allá de la postergación a una situación de carencia material evidente. Tal y como ha reiterado el Tribunal Constitucional, "dada la configuración de los Grupos Parlamentarios en los actuales Parlamentos [...] como entes imprescindibles y principales en la organización y funcionamiento de la Cámara, así como en el desempeño de las funciones parlamentarias y los beneficios que conlleva la adquisición de tal status, aquella facultad constituye una manifestación constitucionalmente relevante del ius in officium del representante". La imposición de la condición de "no adscrito" implica, en definitiva, una capitis diminutio en la intensidad del ejercicio del artículo 23.1 de la Constitución ${ }^{8}$, que entendemos compromete al órgano de gobierno de la cámara a una labor de supervisión que desde luego dista mucho del mero acto de toma en conocimiento.

No es de extrañar, en este sentido, que la Mesa del parlamento andaluz, en resolución del 5 de noviembre de 2020, rectificara y estimara la solicitud de reconsideración, de tal forma que se ofreciera una posibilidad real a los afectados de contradecir los hechos con base a los cuales la Portavoz del grupo parlamentario había comunicado la baja en el grupo de los ocho parlamentarios. Se hace alusión en la resolución de la Mesa a la circunstancia de que, mediante la solicitud, había sido

7 STC, 64/2002, de 11 de marzo, fundamento jurídico 3. Para una aproximación general a la naturaleza del grupo parlamentario, véase en extenso, el trabajo de JOSE MARÍA MORALES ARROYO, Los grupos parlamentarios en las Cortes Generales, Centro de Estudios Políticos y Constitucionales, 1990 o MANUEL CARRASCO DURAN, "Grupos parlamentarios y Ley de Partidos: La organización interna de la Cámara y el poder judicial", en Relaciones entre el poder legislativo y el poder judicial, 2007. Recientemente se ha ocupado en extenso de estas cuestiones DAVID DELGADO RAMOS, "Sobre la constitución de grupos parlamentarios y el «préstamo» de diputados y senadores", em

Teoría y realidad constitucional, N. ${ }^{\circ} 43,2019$, págs. 499-513, y más extenso en su monografía Problemas actuales del Derecho Parlamentario, Aranzadi, 2018.

8 Véase, en sentido crítico, EDMUNDO MATIA PORTILLA, "Naturaleza, composición, estructura orgánica y funcionamiento de las Cortes de Castilla y León”, Sáez Hidalgo, Ignacio [Dir.]: Derecho Público de Castilla y León. Lex Nova, Valladolid, 2008, pp. 257-310. De entre la jurisprudencia constitucional, cabe destacar la STC 246/2012, en la que se declara la inconstitucionalidad del art. 33.3 de la Ley 2/2003, de Administración Local de la Comunidad de Madrid, al interpretar que "la exclusión absoluta de los concejales no adscritos del derecho a asistir a las comisiones informativas y participar [...] en sus deliberaciones no es conforme a los derechos del cargo electo garantizados por el art. 23.2 CE, porque supone dificultar la posterior defensa de las posiciones políticas de los miembros no adscritos [...], incidiendo por ello de forma negativa en el núcleo de las funciones de representación que son propias del cargo de concejal individualmente considerado". 
cuestionada la expulsión por los afectados. En cualquier caso, parece razonable concluir que, en todo caso, la Mesa debería desde un primer momento haber permitido ofrecer sus razones a los diputados dados de baja, antes de proceder, tal y como en un principio hizo, a dar eficacia constitutiva al mero acto de toma en conocimiento.

De todas las formas, la Mesa de la Cámara ha ratificado finalmente la comunicación de la baja hecha por la Portavoz de Adelante Andalucía, con el beneplácito de todos los grupos a excepción del Partido Popular, único que se abstuvo. La mesa no atendió así al argumento principal sobre el cual los diputados excluidos del grupo habían construido su recurso. Dicho argumento es que su candidatura por Adelante Andalucía no fue consecuencia de su militancia política sino del concurso en unas primarias para las cuales no era condición la pertenencia a ninguna de las formaciones políticas que integraban la coalición Adelante Andalucía ${ }^{9}$. Desde luego, esta circunstancia invita a la reflexión de hasta qué punto, ante formaciones políticas cuya plataforma electoral ya no responde a los cánones clásicos y donde hay una legitimidad originaria en la candidatura no mediada por los órganos del partido sino no por los afiliados o incluso por los simpatizantes, es posible mantener los presupuestos lógicos hasta ahora vigentes sobre el transfuguismo ${ }^{10}$. La pregunta fundamental es la de si en este contexto participativo dentro de los partidos, y ante la inexistencia de una procedimiento específico dentro del reglamento parlamentario, como es el supuesto en el que nos encontramos, cabe una interpretación como la llevada a cabo por la mesa del Parlamento andaluz, en la que, en último término, el diagnóstico de un determinado sector del grupo parlamentario acerca de la condición de trásfugas de determinados diputados, opera con una suerte de presunción de veracidad cuyo efecto es reducir de forma drástica las condiciones de ejercicio del cargo representativo de los diputados expulsados.

La respuesta a esta pregunta compete ahora al Tribunal Constitucional, al haber interpuesto los diputados afectados por la expulsión, recurso de amparo frente a la decisión de la Mesa. El Tribunal tendrá aquí la oportunidad de acotar, en el ámbito puramente parlamentario, y no ya en el municipal, los límites que puedan

9 Cabe llamar la atención, aunque no se trate de un supuesto análogo, sobre lo previsto por el Reglamento del Parlamento catalán para el supuesto de coaliciones. En caso "de expulsión del grupo parlamentario de todos los diputados de una formación política integrados en el seno de una coalición o federación... los diputados afectados han de pasar al Grupo Mixto" y no adquieren la condición más gravosa de No adscritos.

10 Presupuestos que creo se cristalizan de forma nítida en el art. 73.3 de la LBRL, donde se establece que cuando uno o varios concejales, incluso siendo la mayoría del grupo institucional, abandona o es expulsado de la formación política que presentó la candidatura, aquellos concejales que permanezcan en dicha formación son los legítimos integrantes del grupo político municipal, pasando el resto a ser considerados como no adscritos. 
derivarse de la condición no adscrito, y, sobre todo, las propias garantías del procedimiento ante el órgano de gobierno de la Cámara.

Por último, cabe señalar que la Presidenta del Parlamento andaluz ha anunciado su intención de reformar el Reglamento de la Cámara, a través del procedimiento de lectura única, para incorporar al mismo el contenido de la última adenda acordada a nivel nacional al pacto antitrasfuguismo, a la que ya se ha hecho referencia. Desde luego, tal incorporación es necesaria de cara a dar cobertura jurídica a un pacto que, como se acaba de ver, en ocasiones despliega sobre el estatuto de los parlamentarios efectos impropios de su modesta naturaleza jurídica. 